Manschot's comments on psychological wellbeing after local resection can only be speculative, because as a pathologist he could not have met many patients treated conservatively, let alone by local resection. Loss of an eye is a significant psychological trauma for most patients and recent studies indicate that quality of life after plaque radiotherapy is superior to that after enucleation, despite the need for follow up (Y Brandberg, E Kock, $S$ Seregard, A F Trampe, Psychological consequences of choroidal melanoma, JERMOV 1995, personal communication). Our patients have selected local resection in preference to enucleation after being fully informed of all the risks and expected outcomes and are therefore highly motivated. Our impression is that very few of these patients express regret about taking this decision, even when complications occur. Nevertheless, formal quality of life studies are necessary and, indeed, are in preparation. These will take into account not only visual acuity but also the visual field, which is often more useful if the fellow eye is healthy.

B DAMATO St Paul's Eye Unit, Royal Liverpool University Hospital, Prescot Street, Liverpool L7 8XP

J PAUL

Clinical Trials Unit, Beatson Oncology Centre, Western Infirmary, Glasgow G11 6NT

W S FOULDS

Ross Hall Hospital, 221 Crookston Road, Glasgow G52 $3 N Q$

1 Early Breast Cancer Trialists' Collaborative Group. Effects of radiotherapy and surgery in early breast cancer. An overview of the randomized trials. N Engl F Med 1995;333:1444-55.

\section{Indications for trans-scleral local resection of uveal melanoma}

EDrToR,-In his recent editorial, ${ }^{1}$ Shields criticises us for not including our indications and contraindications for local resection of uveal melanoma. Our indications and contraindications are, indeed, different from his and we thought it would be useful to itemise them as follows:

(1) A large tumour thickness and secondary retinal detachment complicate radiotherapy but facilitate local resection. Ruthenium plaque radiotherapy is contraindicated for tumours more than $5 \mathrm{~mm}$ thick and, with larger tumours, iodine plaque radiotherapy and charged particle radiotherapy have a high complication rate. ${ }^{23}$ Our main indication for local resection, therefore, is a tumour size deemed excessive for radiotherapy.

(2) A tumour is not inoperable just because it has a large basal diameter $(>15 \mathrm{~mm})$. Statistical studies show that large diameter is not an independent risk factor for visual loss. ${ }^{4}$ There is an increased risk of local tumour recurrence, however, so that special precautions, such as wide clearance margins and adjunctive treatment, are necessary. ${ }^{5}$ Although there is an increased probability of metastatic disease, ${ }^{6}$ this is no worse than after enucleation.?

(3) Tumour extension to within one disc diameter of the optic disc is not a contraindication. Although the risks of local tumour recurrence, ${ }^{5}$ and retinal detachment are increased, both of these complications are usually preventable and treatable, unlike radiational optic neuropathy, which causes severe visual loss and neovascular complications.

(4) Tumour proximity to the fovea is not a contraindication, because although central visual loss may be inevitable, this is also the case with any other form of treatment. Preservation of the temporal field of vision is worthwhile even if central vision is good in the fellow eye. For many patients, preservation of both eyes is important not only for self esteem, but also for social and occupational reasons.

(5) Retinal invasion is not a contraindication, because it is usually possible to preserve an intact retina, prevent retinal detachment by external plombage and photocoagulation, and prevent local tumour recurrence by photocoagulation and plaque radiotherapy. Retinal perforation by tumour causes problems not only with local excision but also after radiotherapy, and if there is vitreous seeding enucleation is the safest option.

(6) Extraocular extension, if small, is not a contraindication, because it can be excised en bloc, with the full thickness scleral defect closed using a lamellar graft from another part of the same eye.

(7) Old age is not in itself a contraindication to local resection despite the use of hypotensive anaesthesia for controlling haemorrhage. If anything, old age facilitates haemostasis because during hypotensive anaesthesia bleeding stops at a higher pressure than is the case in younger patients. We have operated on patients older than 75 years of age without incurring systemic complications and, statistically, old age is not a risk factor for visual loss. ${ }^{4}$

(8) Diffuse melanomas are very aggressive, and best treated by enucleation.

(9) Involvement of more than a third of ciliary body or angle creates difficulties not only for local resection but also radiotherapy, and is an indication for enucleation unless the patient is extremely reluctant to lose the eye, when some form of combination treatment may be attempted.

(10) Optic disc involvement is usually a contraindication, although in some cases it is possible to peel the tumour away from the disc and treat the area by photocoagulation.

(11) Systemic contraindications to systemic hypotensive anaesthesia vary from anaesthetist to anaesthetist, and include any significant circulatory, cardiac, pulmonary, hepatic, or renal insufficiency. Diabetes mellitus is not a contraindication.

(12) As with any surgical procedure, local resection (which includes vitrectomy as an integral part of the procedure) should be performed only by surgeons who have a sufficient competence in the technique and the ability to deal with recurrent tumour. Incomplete excision and local tumour recurrence are not associated with an increased incidence of metastatic disease ${ }^{6}$; however, adjunctive plaque radiotherapy seems to improve the chances of survival ${ }^{6}$ so that it is now difficult to justify local resection without additional treatment.

Unlike Shields, we do not consider local resection to be 'a time consuming procedure which requires more complicated postoperative care'. The procedure is usually completed within 3 hours, depending on the size of the scleral flap, and this is comparable with many vitreoretinal procedures. Patients return to a general ophthalmic ward after about 2 hours in a recovery suite. They are mobile on the first postoperative day and are allowed home on the third postoperative day. Subsequent follow up is the same as for any other form of conservative therapy for uveal melanoma.

B DAMATO St Paul's Eye Unit, Royal Liverpool University Hospital, Prescot Street, Liverpool L7 8XP W S FOULDS Ross Hall Hospital, 221 Crookston Road, Glasgow G52 3NQ

1 Shields JA. Local resection of uveal melanoma. [Editorial] Br F Ophthalmol 1996;80:97-8.

2 Char DH, Quivey JM, Castro JR, Kroll S Phillips T. Helium ions versus iodine 125 brachytherapy in the management of uveal melanoma. Ophthalmology 1993;100:1547-54.

3 Zografos L, Perret C, Gailloud C. Conservative treatment of uveal melanomas by accelerated proton beam. In: Bornfeld N, Gragoudas ES, Hopping W, Lommatzsch PK, Wessing A, Kugler, 1991:497-506.

4 Damato BE, Paul J, Foulds WS. Predictive factors of visual outcome after local resection of choroidal melanoma. Br $\mathcal{F}$ Ophthalmol 1993;77: 616-23.

5 Damato BE, Paul J, Foulds WS. Risk factors for residual and recurrent uveal melanoma after transscleral local resection. $\mathrm{Br} \mathcal{F}$ Ophthalmol 1996;80:102-8.

6 Damato BE, Paul J, Foulds WS. Predictive factors for metastasis after trans-scleral local factors for metastasis after trans-scleral local
resection of uveal melanoma. $\mathrm{Br} f \mathrm{Ophthalmol}$ resection of uveal

7 Foulds WS, Damato BE, Burton RL. Local resection in the management of choroidal melanoma. In: Bornfeld N Gragoudas ES, Hopping W, Lommatzsch PK, Wessing A, Zografos $\mathrm{L}$, eds. Proceedings of the international symposium on tumors of the eye. Amsterdam: Kugler, 1991:553-60.

\section{Reply}

EDITOR,-In their response to my editorial, Damato and Foulds state that I criticised them for not publishing their indications for local resection of uveal melanoma. I re-read the editorial and I do not believe that I was critical. I am sure that Drs Damato and Foulds are aware of my admiration for their pioneering work. However, since they had not mentioned their indications, I felt it would be appropriate to summarise for the readers of the $B \mathcal{F O}$ what I believe to be the current relative indications and contraindications for local resection, based on personal experience. In the editorial I stated that my comments regarding the indications 'represent a personal viewpoint that may differ somewhat from that of Damato and associates'. I also stressed that our indications and contraindications were relative ones and there are no absolute rules.

I find that our differences are minor but they do warrant further comment, based on our personal experience. ${ }^{1}$

(1) My colleagues and I agree that tumours with greater tumour thickness and secondary retinal detachment can be successfully resected and that retinal detachment may actually facilitate the procedure. However, we do not agree that thicker tumours in the peripheral choroid and ciliary body have such a high complication rate following plaque radiotherapy. The main complication is cataract but the ophthalmologist can remove a cataract with restoration of vision, provided that there is no significant posterior radiation retinopathy. Cataract is certainly a common problem after local resection as well. We have treated with plaques many patients with ciliary body tumours greater than 3 clock hours with satisfactory results and we are generally happy that we did not attempt to resect the tumours. After plaque radiotherapy for peripheral melanomas, the visual acuity usually remains 
good for many months and the patients do not have the visual loss that is often present following resection or large ciliary body tumours. When the tumour is too large to resect or irradiate without profound visual loss, enucleation is preferable.

(2) We agree that some tumours with basal diameter greater than $15 \mathrm{~mm}$ can be resected with good results. However, as basal tumour diameter increases, the expected visual outcome is generally worse.

(3) Our experience suggests that transpupillary thermotherapy ${ }^{2}$ (Shields CL, Shields JA, De Potter P, Kheterpel S, Transpupillary thermotherapy in the management of choroidal melanoma, submitted), plaque radiotherapy ${ }^{3}$ (De Potter P, Shields CL, Shields JA, Cater JR, Brady LW, Plaque radiotherapy for juxtapapillary choroidal melanoma. Visual acuity and survival outcome, submitted), or enucleation, depending on tumour size and other factors, are generally preferable to local resection for tumours that extend to within $1 \mathrm{~mm}$ of the optic disc. Although radiation papillopathy can occur after plaque radiotherapy of juxtapapillary melanoma, it generally causes no more visual loss than local resection.

(4) We believe that plaque radiotherapy is preferable for juxtafoveal or subfoveal melanoma. The visual loss is usually more gradual and not as severe as with resection, which leads to immediate and profound visual loss.

(5) We agree that retinal invasion is not an absolute contraindication to resection.

(6) We agree that a small degree of extraocular extension of melanoma is not an absolute contraindication to resection. However, we have had considerable experience and good results with plaque radiotherapy for uveal melanomas with extrascleral extension.

(7) We agree that older age is not an absolute contraindication to resection, but we are generally reluctant to perform resection in very old patients who are in poor general health.

(8) We agree that diffuse melanomas should often be managed by enucleation. However, we have recently reviewed our experience and found that many early diffuse choroidal melanomas can be successfully treated with plaque radiotherapy. ${ }^{4}$

(9) We agree that tumours that involve more than a third of the pars plicata should generally not be managed by resection. However, we are not as pessimistic concerning the results of radiotherapy in such cases, as suggested above.

(10) Optic disc involvement by melanoma is generally a contraindication to local resection. However, some juxtapapillary melanomas can be treated successfully with plaque radiotherapy. ${ }^{3}$

(11) We agree with their systemic contraindications.

(12) We agree that local resection of uveal melanoma should be done by competent surgeons who have had training and experience with this difficult technique.

(13) Compared with plaque radiotherapy, thermotherapy, and enucleation, local resection is definitely a more time consuming procedure and requires much more postoperative care. Because of the increased potential for prolonged vitreous haemorrhage, vitreoretinal traction, and retinal detachment, the postoperative care is more detailed and may require additional surgical procedures.

As indicated above, my colleagues and I have great respect and admiration for Drs Damato and Foulds and we believe that their continued contributions will ultimately benefit patients with posterior uveal melanoma However, we must be cognizant of the fact that no two melanomas are exactly alike and each case must be individualised. In selected cases radiotherapy, thermotherapy, or enucleation may be preferable to local resection, depending on the overall clinical situation and the preference of the informed patient. ${ }^{5}$

JERRY A SHIELDS Director, Ocular Oncology Service Wills Eye Hospital, Philadelphia, USA

1 Shields JA, Shields CL, Shah P, Sivalingam V. Partial lamellar sclerouvectomy for ciliary body and choroidal tumours. Ophthalmology 1991;98:971-83.

2 Oosterhuis JA, Journee-de Korver H, Kakebeeke-Keeme HM, Bleeker JC. Transpupillary thermotherapy in choroidal melanoma. Arch Ophthalmol 1995;113:315-21.

3 De Potter P, Shields CL, Shields JA, Cater JC Tardio DJ. The impact of enucleation versus plaque radiotherapy in the management of juxtapapillary choroidal melanoma on patien survival. Br f Ophthalmol 1994;78:109-14.

4 Shields CL, Shields JA, De Potter P, Cater J, Tardio D, Barrett J. Diffuse choroidal melanoma: clinical features predictive of metastasis. Arch Ophthalmol (in press).

5 Shields JA. Counselling the patient with a posterior uveal melanoma. [Editorial] Am $\mathcal{f}$ Ophthalmol 1988;106:88-91.

\section{BOOK REVIEWS}

General Ophthalmology, 14th ed. By D G Vaughan, T Asbury, P Riordan-Eva. Pp 436. \$41.95. Stamford, CT: Appleton \& Lange, 1995.

That this is the 14th edition of this text is testimony to its popularity. As ever, it succeeds in encapsulating in a medium sized text the current practice of ophthalmology in a remarkably readable style at an economical cost. It is the ideal starter text for the early ophthalmologist and is also of value to the experienced as it provides a comprehensive but concise distillation of clinical knowledge and therapeutics with helpful tables which provide rapid reference for the busy clinician. Although it is suggested as a possible undergraduate text it is far beyond the spectrum of knowledge required of a student although it may be useful as an undergraduate reference text. The illustrations are clear but clinica photographs are not in colour and of relatively poor quality. This detracts minimally from the text. Unlike many similar texts this book has useful chapters on such topics as anatomy and embryology, genetics, preventive ophthalmology, lasers in ophthalmology, and commonly used eye medication. The chapter on neuroophthalmology has been significantly revised and there have been major changes to other chapters, thoroughly updating the text. For those seeking further information there are key references provided at the end of each chapter.

$S$ T D ROXBURGH

Intraocular Lens Power CalculationsAvoiding the Errors. By H John Shammas. Pp 192. \$69. Lynwood, CA: News Circle Publishing House, 1996.

The author of this short text on intraocular lens power calculations has a long standing interest in ophthalmic ultrasound and biometry. The first three chapters describe the formulas which are, or have been, used in intraocular lens power calculations. Some of this may be beyond those of us who are not mathematically inclined but it is interesting to see how the early theoretical formulas were superseded by regression formulas (SRK I and II). Now there is a swing back to theoretical formulas as surgeons strive to achieve greater accuracy in the prediction of postoperative ametropia.

The technique of axial eye length measurement is described with proper emphasis on the pitfalls which can trap the unwary relying on automated biometry. There is a short section on keratometry which includes a discussion on the assessment of the eye which has undergone photorefractive keratectomy or radial keratotomy. The two final chapters discuss the selection of the most appropriate intraocular lens power for the individual patient and the reasons for the unexpected postoperative result.

While some of the detail in this book is complex it would be a useful reference source for those non-medical personnel undertaking biometry and any ophthalmologist who is occasionally disappointed by an unwelcome postoperative refraction.

\section{R C BOSANQUET}

Atlas of Clinical Ophthalmology. By D M Albert and F A Jakobiec. Pp 624. £165. London: W B Saunders, 1995.

A new era of continuing medical education has started and there isn't any better form of CME than to sit down and browse through this excellent book. The value of this book is in stimulating the recapitulation of information acquired elsewhere: one recruits to one's reading vastly more than is bound within this book.

Principles and Practice of Ophthalmology by the same editors was judged by the Association of American Publishers to be the outstanding medical text of 1994 -quite correctly in my view. This atlas contains over 1600 pictures from that six volume set, and many of them are in three, four, or five parts. The scope of the contents is therefore unprecedented for an atlas. The quality of reproductions is superb, with scarcely a single exception. Figure legends are helpful and succinct. In short, the entire volume is simply magnificent.

The organisation of the atlas is good in two respects. Different phases of a single case history are presented as a group showing early, late, and treated stages; and, secondly, important clinical differential diagnoses are juxtaposed: lymphoma of the lacrimal gland against pleomorphic adenoma, and astrocytic hamartoma of the retina against retinoblastoma, for example, and a whole panel of photographs illustrates and compares different neurodegenerative diseases of the retina. This is a very helpful feature throughout the book, and if that means there is occasional duplication of material, so be it.

The other main theme in this atlas is the depiction of pathology and clinical material side by side. Indeed, it constitutes a superb clinicopathological conference. The spectrum of histopathology, gross specimens, scanning and transmission electron microscopy, microbiology, immunohistochemistry, cytology, and radioimaging which is used to illuminate the clinical material here is amazing and entirely 